\section{Pronounced effects on switching efficiency of diarylcycloalkenes upon cycloalkene ring contraction $\dagger$}

\author{
Dmytro Sysoiev, ${ }^{a}$ Tetyana Yushchenko, ${ }^{a}$ Elke Scheer, ${ }^{b}$ Ulrich Groth, ${ }^{a}$ Ulrich E. Steiner, ${ }^{a}$ \\ Thomas E. Exner ${ }^{* a}$ and Thomas Huhn $* a$
}

Received 7th August 2012, Accepted 4th October 2012

DOI: $10.1039 / \mathrm{c} 2 \mathrm{cc} 35726 \mathrm{~g}$

Several difurylperfluorocyclobutenes showing reversible photochromism were synthesized. In comparison to their cyclopentene homologues they show enhanced quantum yields for ring opening but reduced quantum yields for ring closure. X-ray structure analysis and quantum chemical calculations provide a conclusive explanation for such a behaviour.

Successful design of photochromic molecular switches requires a detailed understanding of the switching mechanism and the factors controlling it. ${ }^{1}$ For example, fatigue resistance, optical properties and kinetics of the switching process of diarylcycloethenes are governed by the types and positions of substituents. ${ }^{1,2}$ For Irie-type molecular switches ${ }^{3}$ ( $c f$. Fig. 1) positions for functionalizations are mainly the bridging unit $\mathrm{A},{ }^{4}$ the heteroatom in the 5-membered-ring $\left(\mathrm{X}=\mathrm{CH}_{2}, \mathrm{~S}, \mathrm{O}, \mathrm{NH}\right){ }^{5}$ the substituents $\mathrm{Y}$ at the reactive center, ${ }^{6}$ and the more peripheral substituents $\mathrm{R}^{7}$ Whereas wide variations of $\mathrm{R}$ and $\mathrm{X}$ have been applied for rational design and tuning of photochemical properties, the substituent $\mathrm{Y}$ is usually restricted to the methyl group, and the structural element A to a 5- or 6-membered ring.

Most photochromic diarylcycloalkenes described so far are based on the dithienylperfluorocyclopentene core $\left(\mathrm{A}=\left(\mathrm{CF}_{2}\right)_{3}\right.$, $\left.\mathrm{X}=\mathrm{S}, \mathrm{Y}=\mathrm{CH}_{3}\right){ }^{1 a, 3,8}$ Many of them show high quantum yields
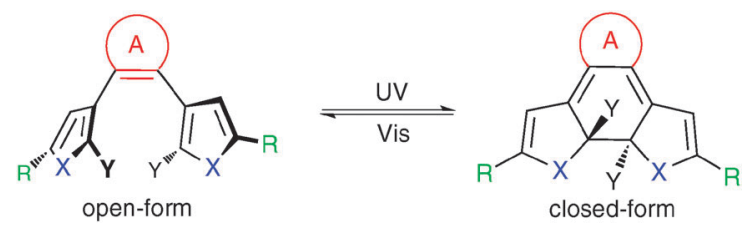

Fig. 1 Schematic representation of photochromic-switching of a diarylcycloalkene. Positions of possible structural variations are marked A, R, X, and $\mathrm{Y}$.

\footnotetext{
${ }^{a}$ Fachbereich Chemie, Universität Konstanz, D-78457 Konstanz, Germany.E-mail: thomas.exner@uni-konstanz.de,

thomas.huhn@uni-konstanz.de

${ }^{b}$ Fachbereich Physik, Universität Konstanz, D-78457 Konstanz, Germany

$\dagger$ Electronic supplementary information (ESI) available: Experimental procedures, spectro-physical data, spectrokinetic measurements, UV/ Vis, NMR spectra, crystallographic data for 1, 2 and 5, procedures of theoretical calculations and animation of the ring-closure sequence in mpeg format. CCDC 832576, 856183 and 832577. For ESI and crystallographic data in CIF or other electronic format see DOI: $10.1039 / \mathrm{c} 2 \mathrm{cc} 35726 \mathrm{~g}$
}

for ring closure, high fatigue resistance under multiple switching and thermal irreversibility of the switching process. Only a limited number of studies dedicated to diarylcyclobutenes are known. They are mostly based on squaric acid and its derivatives as ring A building blocks. ${ }^{9}$ Recently, we synthesized a series of difurylperfluorocyclopentene $(\mathrm{C} 5 \mathrm{~F}-)^{10}$ derived photochromic molecules, with $\mathrm{X}=\mathrm{O}$, so that unspecific bond formation of the thiophene sulphur to metal contacts in molecular electronics applications is avoided. ${ }^{11}$ Structural variations were restricted to heteroatoms in R-group substituents extending the $\pi$-system. ${ }^{12}$ Upon irradiation with UV-light, these systems showed high quantum yields for switching from the open to the closed form, while the reverse photoreaction, a cycloreversion under visible light, proceeded with very low quantum yields in the case of R-substituents with an extended $\pi$-system. This asymmetry of the quantum yield represents a major drawback for the application of these species in optoelectronic applications. Therefore, we became interested in exploring the effects of cyclobutene as a ring $\mathrm{A}$ building block which might facilitate the opening reaction due to an anticipated higher ring-tension of the closed form. Perfluorocyclobutene was chosen in order to decrease the possibility of $(2+2)$-cycloaddition of air oxygen at the double bond of the central ring compared with nonfluorinated ones and an anticipated higher thermal stability which becomes significant in continuous illumination experiments. ${ }^{13}$

Herein we report the synthesis and switching properties of hitherto unknown perfluorocyclobutene-derived bisfurylethenes. Based on combined synthetic, spectrokinetic, and theoretical studies we demonstrate a systematic enhancement of the photochemical quantum yield of ring opening by reducing the size of ring A from 5 to 4 atoms. Such a behaviour makes bisfurylcyclobutenes interesting candidates for further studies in molecular electronics.

Starting from 4-bromo-5-methyl-2-furaldehyde neopentyl acetal, ${ }^{14}$ lithiation and subsequent reaction with perfluorocyclobutene yielded neopentyl acetal C4F-NPA (1) (Scheme 1). Deprotection of $\mathbf{1}$ in a tetrahydrofuran-acetone mixture by slowly adding concentrated hydrochloric acid at $10-15^{\circ} \mathrm{C}$ gave dialdehyde 2 in $90 \%$ yield. Synthesis of the $\pi$-conjugated methylthiosemicarbazone C4F-MTSC (3) and thiosemicarbazone C4F-TSC (4) was achieved in $94 \%$ and $91 \%$ yield, respectively, by azomethine formation with dialdehyde $\mathbf{2}$ and the respective hydrazine derivatives in boiling ethanol, catalyzed by acetic acid. ${ }^{15}$ As a reference compound for assessing the influence of the heteroatom on the 

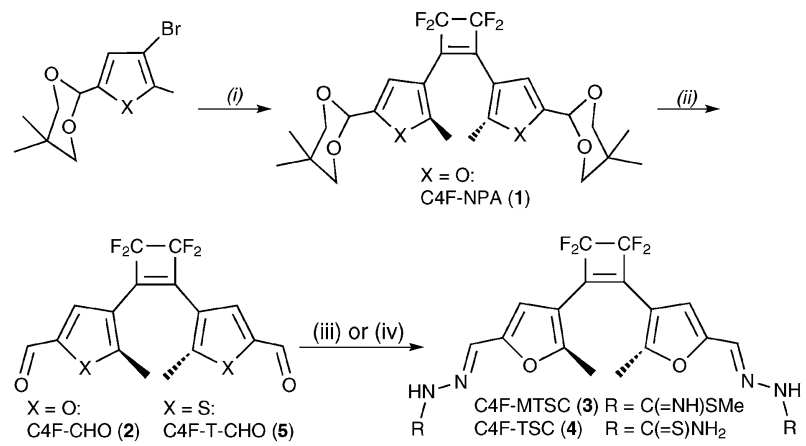

Scheme 1 Synthesis of photochromic diarylcyclobutenes with varying $\pi$-conjugated side chains. Reagents and conditions: (i) $t$ - $\mathrm{BuLi},-78^{\circ} \mathrm{C}$, then $\mathrm{PF}$-cyclobutene; (ii) $\mathrm{H}^{+}$, THF-Acet., $10-15^{\circ} \mathrm{C}$; (iii) $\mathrm{MeS}(\mathrm{C}=\mathrm{NH}) \mathrm{N}_{2} \mathrm{H}_{3}$, $\mathrm{MeOH}$, room temp.; (iv) $\mathrm{H}_{2} \mathrm{~N}(\mathrm{C}=\mathrm{S}) \mathrm{N}_{2} \mathrm{H}_{3}, \mathrm{MeOH}$, room temp.

optical and photokinetic properties, thiophene derivative 5 was also synthesized. Starting from 4-bromo-5-methylthiophene-2carbaldehyde neopentyl acetal, ${ }^{16} \mathbf{5}$ was prepared in $69 \%$ yield using the analogous procedure as for aldehyde $\mathbf{2}$.

To analyze the effect of the perfluorocyclobutene ring on the structure of the newly synthesized diarylethenes, X-ray diffraction analysis of 1, 2 and $\mathbf{5}$ was performed ( $c f$. ESI $\dagger$ ). Suitable crystals of C4F-NPA (1) were grown from a saturated solution of $\mathbf{1}$ in $n$-hexane at $-20{ }^{\circ} \mathrm{C}$ while 2 was crystallized from $\mathrm{CHCl}_{3}$ by slow evaporation. Both, $\mathbf{1}$ and $\mathbf{2}$ crystallize as pairs of atropisomers and adopt a conformation of $C_{2}$-symmetry in the solid state. With the reactive carbon centers $\mathrm{C} 10 / \mathrm{C} 19$ (1) and C5/C15 (2) 6.00-6.10 apart (Fig. 2, left), $\mathbf{1}$ and $\mathbf{2}$ are incapable of switching in the solid state. The distance of the olefin $\alpha$-atoms (C9, C16) in 1 (3.43 $\AA$ ) and $(\mathrm{C} 4, \mathrm{C} 11)$ in 2 (3.48 $\AA$ ), as well as the dihedral angle C9-C12-C13-C16 $\left(9.4-12.5^{\circ}\right)$ for both atropisomers of $\mathbf{1}$ and $\mathbf{2}$, compare very well with the data reported for the squaric acid derivatives. ${ }^{9 b, c}$ While the torsion angle is quite similar in the C5Fhomologue, the distance between the olefin $\alpha$-atoms is distinctly shorter $\left(3.25 \AA\right.$ ) in the latter (vide infra). ${ }^{12}$ Single-crystals of thiophene derived $\mathrm{C} 4 \mathrm{~F}-\mathrm{T}-\mathrm{CHO}$ (5) were grown by slow recrystallization from chloroform. This compound adopts the reactive conformation in the solid, with the aldehyde groups pointing away from the cyclobutene core and the reactive carbon atoms $\mathrm{C} 5$ and $\mathrm{C}^{\mathrm{i}}$ in close proximity (Fig. 2, right). The dihedral angle $\mathrm{C} 4-\mathrm{C} 7-\mathrm{C}^{\mathrm{i}}-\mathrm{C} 4^{\mathrm{i}}\left(9.19^{\circ}\right)$ as well as the distance between the reactive carbon atoms $\mathrm{C} 5$ and $\mathrm{C} 5^{\mathrm{i}}(3.90 \AA)$ are larger than in the 5 -ring homologue $\mathrm{C} 5 \mathrm{~F}-\mathrm{T}-\mathrm{CHO}\left(6.2^{\circ}, 3.60 \AA\right) .{ }^{17}$ This is a consequence of the smaller size of the alkene ring in $\mathbf{5}$ compared to its C5-homologue. The distance between olefin $\alpha$-atoms $\mathrm{C} 4-\mathrm{C} 4{ }^{\mathrm{i}}$ amounts to $3.58 \AA$ in $\mathbf{5}$ and is comparable

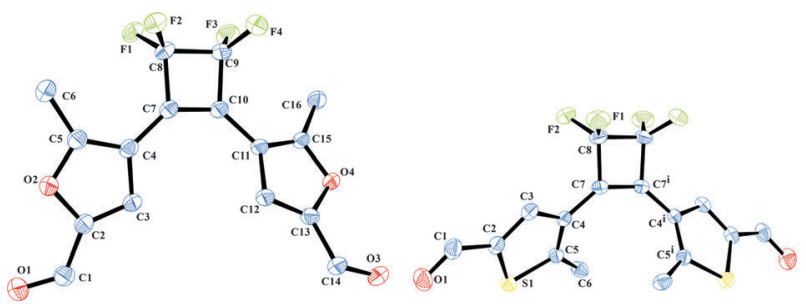

Fig. 2 Molecular structure of difurylperfluorocyclobutene 2 (left) and dithienyl perfluorocyclobutene $\mathbf{5}$ (right). Ellipsoids are drawn at the $50 \%$ probability level. Hydrogen atoms are omitted for clarity. with corresponding distances in $\mathbf{1}$ and $\mathbf{2}$ but it is much longer than in the hexafluorocyclopentene C5F-T-CHO (3.24 $\AA$ ).

All difurylperfluorocyclobutenes showed reversible photochromism when irradiated in solution. The open forms have their first absorption bands around $300 \mathrm{~nm}$. For the $\pi$-conjugated derivatives 3 and $\mathbf{4}$ this band is shifted by $30 \mathrm{~nm}$ to longer wavelengths. The closed forms absorb in the visible region and are deeply colored (for UV/Vis spectra, absorption spectra and spectrokinetic measurements $c f$. ESI $\dagger$ ).

In Table 1, the quantum yields of the difurylperfluorocyclobutenes are compared with those of corresponding difurylperfluorocyclopentenes. For the NPA substituted compounds with a saturated substitutent of the base chromophore, the only effect is a moderate decrease of the quantum yield of ring closure on going from $\mathrm{C} 5 \mathrm{~F}$ to $\mathrm{C} 4 \mathrm{~F}$. For the compounds with $\pi$-substituents, however, the changes are quite pronounced. In comparison to the $\mathrm{C} 5 \mathrm{~F}$ compounds the $\mathrm{C} 4 \mathrm{~F}$-derived molecules show reduced quantum yields for ring closure, but enhanced quantum yields for ring opening, although the latter effects are less pronounced.

As generally observed, ${ }^{2 a, 3,12}$ in compounds of the C5F-type, the quantum yields of ring opening drop to quite low values when extending the $\pi$-system by unsaturated substituents. These observations have been assigned to a less reduced anti-bonding nature of the central photogenerated $\mathrm{C}-\mathrm{C}$ bond in the excited singlet state ${ }^{3}$ and/or enhanced radiationless decay due to the higher degree of rotational flexibility in a more extended $\pi$-system. ${ }^{12}$ The present results show the same trend for the quantum yield of ring opening in the C4F-compounds, although their absolute values are by a factor of 2-3 larger than for the corresponding C5F-compounds. On the other hand, extended $\pi$-conjugation has little effect on the quantum yields of ring closure in the C5F-compounds but causes a huge decrease in the quantum yields of ring closure in the C4F-compounds. Altogether, these findings reveal the important role of ring tension in the [4,6]-ring system, which supports the opening of the cyclohexadiene ring in the closed form but impedes its closing in the open form.

To address this point in more detail, quantum chemical calculations using the CASSCF method ${ }^{19}$ of the ground $\mathrm{S}_{0}$ and excited $\mathrm{S}_{1}$ states were performed for compounds $\mathrm{C} 4 \mathrm{~F}-\mathrm{CHO}$ and $\mathrm{C} 5 \mathrm{~F}-\mathrm{CHO}$ with the shortest extension of the $\pi$-system (Fig. 3). Details of these calculations can be found in the ESI. $\dagger$ From the $\mathrm{S}_{1}$ closed state $(\mathrm{H})$ up to the transition state $(\mathrm{G})$ the picture is almost indistinguishable for both molecules. Energy uptake by the vertical excitation is sufficient to overcome the

Table 1 Photochemical quantum yields for ring-opening and closing reactions of C4F-vs. C5F-diarylcycloalkenes ${ }^{a}$

\begin{tabular}{llllll}
\hline & \multicolumn{2}{l}{$\phi_{\mathrm{o} \rightarrow \mathrm{c}}(313 \mathrm{~nm})$} & & \multicolumn{2}{l}{$\phi_{\mathrm{c} \rightarrow \mathrm{o}}\left(\lambda_{2}[\mathrm{~nm}]\right)$} \\
\cline { 2 - 3 }$\pi$-Substituent & C4F- & C5F- & & C4F- & C5F- \\
\hline NPA & 14 & 20 & & $8.6(438)$ & $9.0(438)$ \\
CHO & $1.0^{b}$ & $34^{b}$ & & $46(576)^{b}$ & $14(576)^{b}$ \\
T-CHO & $2.6^{b}$ & $86(351)^{c}$ & & $8.8(576)^{b}$ & $3.6(514)^{c}$ \\
TSC & 0.024 & $28^{d}$ & & $2.4(576)$ & $0.49(576)^{d}$ \\
MTSC & 0.039 & $38^{d}$ & & $1.0(576)$ & $0.32(576)^{d}$
\end{tabular}

${ }^{a}$ In $\%$, given with a precision of two significant digits, solvent $\mathrm{CHCl}_{3}$, unless stated otherwise; for details of the photokinetics and UV/vis spectra see ESI; ${ }^{b}$ Solvent $\mathrm{CH}_{3} \mathrm{CN} .{ }^{c}$ Solvent toluene. ${ }^{18 d}$ Solvent $\mathrm{MeOH} .{ }^{12}$ 


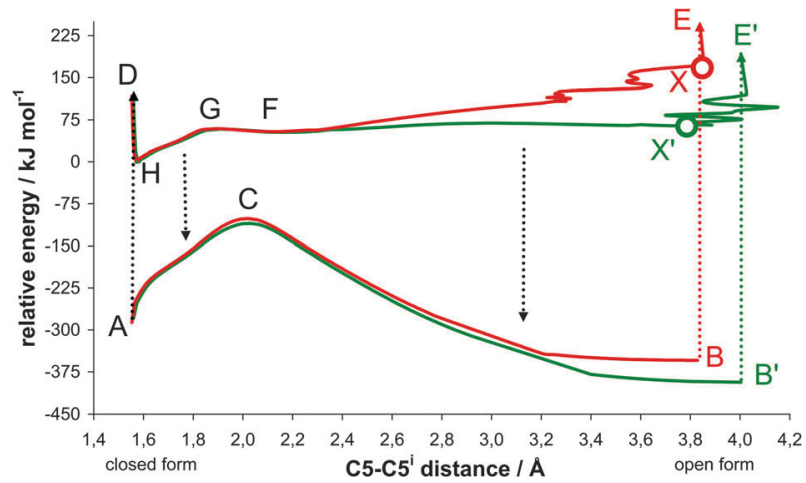

Fig. 3 Energy profiles of the ground $\left(\mathrm{S}_{0}\right)$ and excited $\mathrm{S}_{1}$ states of $\mathrm{C} 4 \mathrm{~F}-\mathrm{CHO}$ (green) and $\mathrm{C} 5 \mathrm{~F}-\mathrm{CHO}$ (red) obtained as relaxation paths following the steepest descent. The $\mathrm{C} 5-\mathrm{C} 5^{\mathrm{i}}$ distance is used as a representative coordinate to specify the molecular conformations. Points marked A and $B\left(B^{\prime}\right)$ represent the energy minima of the $S_{0}$ states of closed and open forms, respectively, of $\mathrm{C} 5 \mathrm{~F}-\mathrm{CHO}(\mathrm{C} 4 \mathrm{~F}-\mathrm{CHO}), \mathrm{C}$ represents the transition state on the $\mathrm{S}_{0}$ surface. For both, $\mathrm{C} 4 \mathrm{~F}$ and $\mathrm{C} 5 \mathrm{~F}$, the energy of the global minimum $H$, representing the relaxed closed $\mathrm{S}_{1}$ state, was taken as the zero value of the energy scale. The encircled points marked $X\left(X^{\prime}\right)$ represent conformations where relaxation mainly changed coordinates other than the $\mathrm{C} 5-\mathrm{C}^{i}$ distance. For further details, especially on the (meta)stable points $\mathrm{C}$ to $\mathrm{H}$ and $\mathrm{X}$ of the $\mathrm{S}_{1}$ surface, $c f$. text.

barrier easily. Therefore, the higher quantum yield of ring opening for $\mathrm{C} 4 \mathrm{~F}$ cannot be explained by a smaller reaction barrier. In contrast, larger differences are seen on the side of the open form. While in C4F the $\mathrm{S}_{1}$ energy landscape is almost flat for $\mathrm{C} 5-\mathrm{C}^{\mathrm{i}}$ (atom numbering $c f$. Fig. 2 right) distances between 2.3 and $3.8 \AA$, a significant energy increase is seen for $\mathrm{C} 5 \mathrm{~F}$ when the two atoms are forced further away from each other. We therefore expect that all C4F molecules, which have overcome the activation barrier $(G)$ starting from the closed Franck Condon state (D), move freely towards the open state on the $\mathrm{S}_{1}$ landscape and can reach the $\mathrm{S}_{0}$ state by radiationless deactivation. In $\mathrm{C} 5 \mathrm{~F}$, most of the molecules will be reflected back to the closed form since they have to move uphill in energy if they follow the reaction coordinate further towards the conformation of the open form.

The steeper energy landscape of C5F may also account for the much better efficiency of ring closure in these compared to the $\mathrm{C} 4 \mathrm{~F}$ compounds. Upon vertical excitation $(E)$, after an initial relaxation to an intermediate conformation $\mathrm{X}$, in which the $\mathrm{C} 5-\mathrm{C} 5^{\mathrm{i}}$ distance is still close to its value in the $\mathrm{S}_{0}$ state of the open form, the open form of $\mathrm{C} 5 \mathrm{~F}$ will further relax to the local minimum $(F)$ and can easily overcome the flat transition state maximum $(G)$ to reach the global minimum $(H)$ of the closed form (see animation in the ESI $\dagger$ ). Differently from $\mathrm{C} 5 \mathrm{~F}$, the open form of $\mathrm{C} 4 \mathrm{~F}$ relaxes to a significantly lower minimum (X). From there, the molecule has to explore the flat energy landscape until it finds the global minimum $(H)$ of the closed form. This process resembles the diffusion of a particle through a medium. While this random search for the minimum is going on, there is a high chance of radiationless deactivation into the $\mathrm{S}_{0}$ state with a subsequent relaxation to the open form.

It is important to note that according to the experimental results ( $c f$. Table $\mathrm{S} 1, \mathrm{ESI} \dagger$ ), as well as the quantum chemical calculations, the size of the ring anellated to the central $\mathrm{C}-\mathrm{C}$ bond has almost no influence on the vertical energy separation of $S_{0}$ and $S_{1}$ states in the open and in the closed form. Thus, different rates for the opening and closing reactions have to be fully attributed to the different relaxation energies in the excited $S_{1}$ state of the open form impeding photocyclization but enhancing, photo-induced ring opening in $\mathrm{C} 4 \mathrm{~F}$ compared to $\mathrm{C} 5 \mathrm{~F}$. These pronounced effects show that central-ring modification might provide a strategy towards rational design of molecular switches showing a more symmetric switching behaviour.

We acknowledge financial support from and helpful discussions within SFB767. The authors are grateful to Bernhard Weibert for collecting the crystallographic data.

\section{Notes and references}

1 (a) H. Tian and S. J. Yang, Chem. Soc. Rev., 2004, 33, 85-97; (b) F. M. Raymo, I. Yildiz and E. Deniz, Chem. Soc. Rev., 2009, 38, 1859-1867.

2 (a) J. Ern, A. T. Bens, H. D. Martin, S. Mukamel, S. Tretiak, K. Tsyganenko, K. Kuldova, H. P. Trommsdorff and C. Kryschi, J. Phys. Chem. A, 2001, 105, 1741-1749; (b) X. Crispin, F. L. E. Jakobsson, P. Marsal, S. Braun, M. Fahlman, M. Berggren and J. Cornil, J. Phys. Chem. C, 2009, 113, 18396-18405; (c) S. J. van der Molen and P. Liljeroth, J. Phys.: Condens. Matter, 2010, 22, 133001.

3 M. Irie, Chem. Rev., 2000, 100, 1685-1716.

4 M. M. Krayushkin, B. V. Lichitskii, D. V. Pashchenko, I. A. Antonov, B. V. Nabatov and A. A. Dudinov, Russ. J. Org. Chem., 2007, 43, 1357-1363.

5 (a) S. Z. Pu, T. S. Yang, J. K. Xu and B. Chen, Tetrahedron Lett., 2006, 47, 6473-6477; (b) S. Z. Pu, H. Li, G. Liu and W. J. Liu, Tetrahedron Lett., 2010, 51, 3575-3579; (c) T. Fukaminato, M. Ohsumi, M. Hazama and M. Irie, Chem. Commun., 2008, 3281-3283; (d) T. Yamaguchi and M. Irie, Tetrahedron Lett., 2006, 47, 1267-1269; (e) Y. Chen, D. X. Zeng, N. Xie and Y. Z. Dang, J. Org. Chem., 2005, 70, 5001-5005.

6 S. Kobatake, D. Kitagawa and K. Sasaki, Bull. Chem. Soc. Jpn., 2011, 84, 141-147.

7 S. L. Gilat, S. H. Kawai and J. M. Lehn, Chem.-Eur. J., 1995, 1, 275-284.

8 (a) V. A. Barachevsky, Y. P. Strokach, Y. A. Puankov, O. I. Kobeleva, T. M. Valova, K. S. Levchenko, V. N. Yaroshenko and M. M. Krayushkin, ARKIVOC, 2009, 70-95; (b) M. Irie, Proc. Jpn. Acad., Ser. B, 2010, 86, 472-483.

9 (a) P. Raster, S. Weiss, G. Hilt and B. König, Synthesis, 2011, 905-908; (b) J. Kühni and P. Belser, Org. Lett., 2007, 9, 1915-1918; (c) M. M. Krayushkin, V. Z. Shirinian, L. I. Belen'kii, A. Y. Shadronov, A. Y. Martynkin and B. M. Uzhinov, Mendeleev Commun., 2002, 141-143; (d) M. Hanazawa, R. Sumiya, Y. Horikawa and M. Irie, Chem. Commun., 1992, 206-207; (e) M. Matsuoka, H. Soejima and T. Kitao, Dyes Pigm., 1991, 16, 309-315.

10 The bisfurylperfluoro(cyclobutene/pentene)-core is represented by $\mathrm{C} 4 \mathrm{~F}$ or $\mathrm{C} 5 \mathrm{~F}$, accordingly. Substituents at the furyl moiety are added to the above cores.

11 Y. Kim, T. J. Hellmuth, D. Sysoiev, F. Pauly, T. Pietsch, J. Wolf, A. Erbe, T. Huhn, U. Groth, U. E. Steiner and E. Scheer, Nano Lett., 2012, 12, 3736-3742.

12 D. Sysoiev, A. Fedoseev, Y. Kim, T. E. Exner, J. Boneberg, T. Huhn, P. Leiderer, E. Scheer, U. Groth and U. E. Steiner, Chem.-Eur. J., 2011, 17, 6663-6672.

13 (a) J. Kühni, J. L. Debieux and P. Belser, Synthesis, 2007, 1421-1425; (b) J. J. D. de Jong, L. N. Lucas, R. Hania, A. Pugzlys, R. M. Kellogg, B. L. Feringa, K. Duppen and J. H. van Esch, Eur. J. Org. Chem., 2003, 1887-1893.

$14 \mathrm{H}$. Haarmann and W. Eberbach, Tetrahedron Lett., 1991, 32, 903-906.

15 E. M. Jouad, G. M. Bouet, M. A. Khan, D. Dogaru and C. Mateescu, Phosphorus, Sulfur Silicon Relat. Elem., 2007, 182, $2705-2718$.

16 A. Osuka, D. Fujikane, H. Shinmori, S. Kobatake and M. Irie, J. Org. Chem., 2001, 66, 3913-3923.

17 S. Z. Pu, S. K. Chan, R. J. Wang, F. S. Zhang, X. H. Zhou, F. Sun and P. Yuan, Z. Kristallogr. - New Cryst. Struct., 2002, 217, 415-416.

18 A. T. Bens, PhD thesis, Heinich-Heine-Universität, Düsseldorf, Germany, 2001

19 D. Hegarty and M. A. Robb, Mol. Phys., 1979, 38, 1795-1812. 